\title{
Oral Health Status of Children with Thalassaemia in Melaka: A Pilot Study
}

Submitted: $24 / 12 / 2020$

Accepted: 7/8/2021

Online: $22 / 12 / 2021$

\author{
Eswara Uma a* , Eby Varghese ${ }^{a}$, Ankita Arora ${ }^{a}$, Shoba S Pathmanathan ${ }^{b}$
}

${ }^{a}$ Department of Paediatric Dentistry, Faculty of Dentistry, Manipal

University College Malaysia, 75150 Melaka, Malaysia

${ }^{b}$ Department of Paediatrics, Hospital Melaka, Ministry of Health, 75400 Melaka, Malaysia

${ }^{\star}$ Corresponding author: eswara.uma@manipal.edu.my

To cite this article: Uma E, Varghese E, Arora A, Pathmanathan SS (2021). Oral health status of children with thalassaemia in Melaka: A pilot study. Arch Orofac Sci, 16(2): 165-175. https://doi.org/ 10.21315/aos2021.16.2.7

To link to this article: https://doi.org/10.21315/aos2021.16.2.7

\begin{abstract}
Thalassemia is an inherited disorder that involves abnormal haemoglobin formation. This cross-sectional study with universal sampling was conducted from May 2018 to January 2019 to evaluate the oral health status of children with thalassaemia. The sample consisted of 54 transfusion-dependent patients between the ages of 3-17 years old, who were registered at the paediatric day-care centre of Hospital Melaka. Oral health status was evaluated which included soft tissue examination, recording of dental caries, malocclusion and oral hygiene status of the children, while their parents answered a pre-validated self-administered questionnaire on sociodemographic and oral health practices and attitudes. The mean deft (decayed, exfoliated and filled teeth) among the 3-5 years old was 6.71 66.07 . The mean DMFT

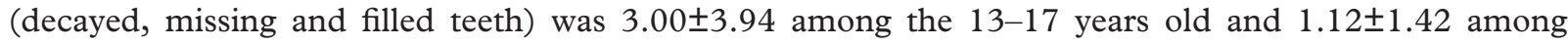
the 6-12 years old. Most of the 3-5 years old children exhibited good oral hygiene (71.4\%). Dentofacial findings among the 3-5 years old were increased overjet $(35.7 \%)$ and open bite $(28.6 \%)$ predominantly. Fractured teeth $(69.2 \%)$, increased overjet $(46.2 \%)$ and discolouration $(23.1 \%)$ were the common dentofacial findings among the 6-12 years old while increased overjet $(71.4 \%)$, soft tissue lesions $(57.1 \%)$ and posterior crossbite $(28.6 \%)$ were seen among the $13-17$ years old. In this cohort of children with thalassaemia, the prevalence of dental caries was high in preschool children and older children.
\end{abstract}

Keywords: Dental caries; dentofacial features; haemoglobinopathy; oral health status; thalassaemia

\section{INTRODUCTION}

Thalassaemias are autosomal recessive disorders, which lead to reduce production of one or more subunits of haemoglobin. Beta-thalassaemia ( $\beta$-thalassaemia) major produces anaemia, which is severe and requires life-long blood transfusions for survival. The defects that occur at the molecular level leading to $\beta$-thalassaemia are heterogeneous and each ethnic group possesses its own specific set of mutations.
The Malaysian population comprises of Malays (65.1\%), Chinese (26\%), Indians $(7.7 \%)$ and other ethnic groups (1.2\%). The presence of single alpha-globin gene deletion is the cause for asymptomatic disorders among Malays, while Malaysian Indians rarely have been found to have thalassaemia. In Malaysia, thalassaemia is a public health problem (Tan et al., 2010).

The estimated annual number of births worldwide with $\beta$-thalassaemia is 40,618 as 
reported by the World Health Organization (WHO) (Modell \& Darlison, 2008). Only a fraction of thalassaemic children worldwide requiring a transfusion get one. Unfortunately, it has been observed that most transfused patients die due to iron overload unless they receive iron chelator therapy. Hence, the need for combined treatment of transfusion and oral iron chelators, as well as prevention programmes arises. It has been observed that in countries where the combined programme is implemented, survival of these children is improving, affected births are falling and the number of patients is stabilising. Of late it has been observed in many countries that thalassaemia is being contained due to the cost-effectiveness of this combined programme (Modell \& Darlison, 2008).

In Malaysia, there was a total of 8,681 thalassaemia patients registered till November 2018 (Mohd Ibrahim, 2019). Moreover, 2,676 (33.52\%) of these have $\beta$-thalassaemia major, $748(9.37 \%)$ have $\beta$-thalassaemia intermedia, 2744 (34.37\%) have HbE- $\beta$-thalassaemia and 1,458 (18.26\%) have $\mathrm{Hb} \mathrm{H}$ disease. Additionally, 358 patients $(4.48 \%)$ have other types of haemoglobinopathies. In this article, it was highlighted that while alpha-thalassaemia ( $\alpha$-thalassaemia) has been observed in Malaysia, its fatal condition, $\mathrm{Hb}$ Bart's hydrops fetalis was observed mainly among Malaysian Chinese. The carrier state for thalassaemia among Malaysians has been estimated to be about 5\% (Mohd Ibrahim, 2019).

Individuals with thalassaemia are found to have frontal bossing, prominent cheekbones and protruding pre-maxilla due to erythroid hyperplasia with depression of the bridge of the nose. A Malaysian study reported a higher prevalence of craniofacial abnormalities among transfusion-dependent thalassaemia patients when the patients had signs of severe disease and received less efficient treatment (Toman et al., 2011). Individuals with thalassaemia show malocclusion of teeth, discoloured teeth, reduced crown size and short roots. Parotid glands seem to be affected along with reduced salivary Ig A. Atrophic candidiasis has been observed in these individuals. They have also been reported to have high dental caries as well as poor oral hygiene (Singh et al., 2013; Helmi et al., 2017; Rajajee et al., 2017).

A study conducted in Dubai observed a high prevalence of dental caries, high calculus index and retained primary teeth among children with $\beta$-thalassaemia (Al-Raeesi et al., 2018). Lack of dental awareness, education and care along with poor oral hygiene and dietary habits play significant roles in the prevalence of dental caries in thalassaemic children (Hattab et al., 2001). While the individuals having thalassaemia must be under constant care of a physician, it further poses challenges to patients and family members at physical, emotional, and cognitive levels leading to disruption of their normal psychosocial life (Wahab et al., 2011).

For further planning and instituting adequate preventive measures and to create awareness among the parents towards the oral health of their children, this pilot study was aimed to evaluate the oral health status of children with thalassaemia in Melaka, Malaysia.

\section{MATERIALS AND METHODS}

This cross-sectional study was conducted from May 2018 till January 2019, among all the 62 transfusion-dependent thalassaemia patients between the ages of 3-17 years old, registered at the paediatric day-care centre of Hospital Melaka. Children suffering from any other disease, which are known to cause dental abnormalities, for example, Down syndrome and uncooperative children were excluded. A universal sampling method was used for this study. Before the start of the study, the ethical clearance was obtained from the institutional ethical board [MMMC/FOD/AR/EC-2018(F-01)] as well medical research and ethical committee 
(MREC) [NMRR-18-556-40347(IIR)], Ministry of Health Malaysia.

Informed consent from the parents was taken before the inclusion of the participant in the study. All the registered patients reported for transfusion at 4-5 weeks intervals. The children with thalassaemia underwent only oral examination on the day they were scheduled for their transfusion and no dental procedures were performed. The oral examination included soft tissue examination, dental caries recording, recording of malocclusion, oral hygiene status and recording of any other oral abnormalities. As the children waited for their blood reports of cross-matching in the paediatric day-care unit, the consented children underwent oral examination followed by their transfusion as per the standard protocol.

There was no interference with the transfusion protocol of these vulnerable children due to oral examination. The oral examination was performed in the daycare centre for the children on the day of transfusion with diligent adherence to the infection control protocol. The parents answered a self-administered questionnaire that collected data about sociodemographic as well as oral health practices and attitudes (Vargas et al., 2000). The questionnaire was translated into bahasa Malaysia and underwent forward and backward translation as well as face and content validation in our institute with the help of experts. All the three trained and calibrated examiners performed the comprehensive oral examination related to dental caries, oral hygiene, malocclusion as well as any other dentofacial abnormalities, while the patient sat on a portable dental chair under illumination with a portable light. A dental surgery assistant helped the examiners in recording the findings on a recording sheet. Dental caries experience was recorded using the WHO index (Petersen et al., 2013). Using this index, it was recorded if the teeth were sound, with dental caries, filled with caries, filled without caries, missing due to caries or missing due to exfoliation (in case of mixed dentition).

Oral hygiene was recorded using oral hygiene index-simplified (OHI-S) (Greene \& Vermillion, 1964), wherein the Debris Index and the Calculus Index was calculated by recording the amount of debris or calculus found on the index tooth surfaces. Occlusion was recorded both in primary and permanent dentition. Primary (terminal plane relationship) and permanent molar relationship (Angle's classification), anterior relationship i.e., open bite, crowding, increased overjet, crossbites in both anterior and posterior segments were recorded. All the children examined were divided into three groups i.e., 3-5 years old, 6-12 years old, and 13-17 years old. Depending on the type of dentition a particular child had, in children up to the age of 12 years old both primary and permanent teeth were examined.

Inter-examiner and intra-examiner reliability were calculated for the recording of OHI-S, dental caries and recording malocclusion. The kappa value for OHI-S, dental caries and malocclusion was found to be $0.87,0.89$ and 0.83 , respectively indicating an almost perfect agreement between the examiners. Descriptive statistics such as frequency and percentage, including mean and standard deviation were calculated for quantitative data. The prevalence (\%) of malocclusion and dentofacial abnormalities were determined.

\section{RESULTS}

While the total registered children in the day-care centre were 62 , four children were excluded as they were below three years old of age, and four children could not be examined as they did not report on the appointed date for transfusion. The total number of children who were examined was 54. Out of the 54 patients evaluated, the majority of them were of Malay origin $(87 \%)$. The number of male patients $(53.7 \%)$ was slightly higher than females 
$(46.3 \%)$ as shown in Table 1 . Almost half of the patients were in the 6-12 years old category. Parental attitude towards reasons for a visit to a dentist showed that most of the parents $(85 \%)$ took their children to a dentist previously for reasons such as check-ups or cleaning of teeth $(50 \%)$, tooth removal $(11.1 \%)$, etc. (see Table 2 ).

Regarding oral hygiene practices, many participants (more than $85 \%$ ) belonging to all three age categories used a toothbrush with toothpaste as the cleaning aid, while $7.4 \%$ in all categories used a toothbrush and water, and for only one child in the 3-5 years old group, a clean cloth was used. Frequency of cleaning teeth two or more times a day was seen to be highest among the $13-17$ years olds $(78.6 \%)$ while it was least among the 3-5 years olds (57.1\%). Among the 3-5 years olds, $42.9 \%$ of them brushed their teeth with their parents' assistance while $28.6 \%$ of them would do the brushing all by themselves. The number of patients brushing their teeth without assistance from parents was higher among the $6-12$ years old $(92.3 \%)$ and $13-17$ years olds (100\%) (see Table 3).

Parental attitude towards the state of their children's teeth and the effect it had on their children showed that although $57.4 \%$ of the parents were satisfied with the appearance of their teeth, some of the parents reported that their children experienced dental problems in the previous year which made them unable to eat hard food (11.1\%). Some parents reported that due to the state of their child's teeth, other children teased their child $(7.4 \%)$, their child avoided smiling (5.6\%), or even missed school (5.6\%) (see Table 4). The mean deft (decayed, exfoliated and filled teeth) among the 3-5 years old was the highest $(6.71 \pm 6.07)$ while it was $3.69 \pm 4.82$ among the 6-12 years old. The mean DMFT (decayed, missing and filled teeth) was

Table 1 Gender and ethnicity of the study population

\begin{tabular}{|c|c|c|c|c|c|}
\hline \multirow[b]{2}{*}{ Study population } & & \multicolumn{3}{|c|}{ Category of age } & \multirow{2}{*}{$\begin{array}{l}\text { Total } \\
n(\%)\end{array}$} \\
\hline & & $\begin{array}{c}3-5 \text { years old } \\
n(\%)\end{array}$ & $\begin{array}{c}\text { 6-12 years } \\
n(\%)\end{array}$ & $\begin{array}{c}13-17 \text { years } \\
n(\%)\end{array}$ & \\
\hline \multirow[t]{3}{*}{ Gender } & Male & $8(57.1)$ & $14(53.8)$ & $7(50.0)$ & $29(53.7)$ \\
\hline & Female & $6(42.9)$ & $12(46.2)$ & $7(50.0)$ & $25(46.3)$ \\
\hline & Total & $14(100.0)$ & $26(100.0)$ & $14(100.0)$ & $54(100.0)$ \\
\hline \multirow[t]{4}{*}{ Ethnicity } & Malay & $13(92.9)$ & $21(80.8)$ & $13(92.9)$ & $47(87.0)$ \\
\hline & Chinese & $1(7.1)$ & $5(19.2)$ & $0(0.0)$ & $6(11.1)$ \\
\hline & Indian & $0(0.0)$ & $0(0.0)$ & $1(7.1)$ & $1(1.9)$ \\
\hline & Total & $14(100.0)$ & $26(100.0)$ & $14(100.0)$ & $54(100.0)$ \\
\hline
\end{tabular}

Table 2 Reason for dental visit in transfusion dependent thalassaemia children

\begin{tabular}{|c|c|c|c|c|}
\hline \multirow[b]{2}{*}{ Reason for visit } & \multicolumn{3}{|c|}{ Category of age } & \multirow{2}{*}{$\begin{array}{l}\text { Total } \\
n(\%)\end{array}$} \\
\hline & $\begin{array}{c}\text { 3-5 years old } \\
n(\%)\end{array}$ & $\begin{array}{c}\text { 6-12 years old } \\
n(\%)\end{array}$ & $\begin{array}{c}13-17 \text { years old } \\
n(\%)\end{array}$ & \\
\hline No previous dental experience with dentist & $5(35.7)$ & $3(11.5)$ & $0(0.0)$ & $8(14.8)$ \\
\hline For check-up & $8(57.1)$ & $10(38.5)$ & $9(64.3)$ & $27(50.0)$ \\
\hline For toothache & $1(7.1)$ & $1(3.8)$ & $1(7.1)$ & $3(5.6)$ \\
\hline $\begin{array}{l}\text { Requested for specific treatment } \\
\text { (e.g., tooth cleaning, fillings, extractions) }\end{array}$ & $0(0.0)$ & $12(46.1)$ & $4(28.5)$ & $16(29.6)$ \\
\hline Total & $14(100.0)$ & $26(100.0)$ & $14(100.0)$ & $54(100.0)$ \\
\hline
\end{tabular}


$3.00 \pm 3.94$ among the 13-17 years old but it was only $1.12 \pm 1.42$ among the $6-12$ years old (see Table 5).

In the 3-5 years old group, four children were caries-free (deft $=0$ ) while in the 6-12 years old group only 10 children were cariesfree in both primary and permanent dentition $(\mathrm{deft}+\mathrm{DMFT}=0)$. In the 13-17 years old group, seven children were caries-free $(\mathrm{DMFT}=0)$. The overall oral hygiene index was found to be fair to good. Among the 3-5 years old, most of the children exhibited good oral hygiene $(71.4 \%)$ while it was only $21.4 \%$ among $13-17$ years old. Most $13-17$ years old exhibited fair oral hygiene (71.4\%). The number of children exhibiting good and fair oral hygiene among the 6-12 years old was almost equally divided. Interestingly, none, or very few children from the three age categories exhibited poor oral hygiene (see Table 6).

Dentofacial findings among the $3-5$ years old was mainly increased overjet $(35.7 \%)$ and open bite $(28.6 \%)$. Fractured teeth $(69.2 \%)$,

Table 3 Oral hygiene practices of transfusion dependent thalassaemia children

\begin{tabular}{lccc} 
& \multicolumn{3}{c}{ Category of age } \\
\cline { 2 - 4 } Oral hygiene practices & $\begin{array}{c}\mathbf{3 - 5} \text { years old } \\
\boldsymbol{n}(\%)\end{array}$ & $\begin{array}{c}\mathbf{6 - 1 2} \text { years old } \\
\boldsymbol{n}(\%)\end{array}$ & $\begin{array}{c}\mathbf{1 3 - 1 7} \text { years old } \\
\boldsymbol{n}(\%)\end{array}$ \\
\hline Toothbrush with toothpaste as cleaning aid for teeth & $12(85.7)$ & $24(92.3)$ & $13(92.9)$ \\
Toothbrush with water & $1(7.1)$ & $2(7.7)$ & $1(7.1)$ \\
Clean cloth & $1(7.1)$ & $0(0.0)$ & $3(0.0)$ \\
Frequency of tooth brushing once a day & $5(36.0)$ & $7(27.0)$ & $11(78.6)$ \\
Frequency of toothbrushing twice or more times a day & $8(57.1)$ & $18(69.2)$ & $0(0.0)$ \\
Toothbrushing assisted by a parent & $6(42.9)$ & $0(0.0)$ & $14(100.0)$ \\
Toothbrushing unaided & $4(28.6)$ & $24(92.3)$ &
\end{tabular}

Table 4 Dental related problems experienced in the previous one year in transfusion dependent thalassaemia children

\begin{tabular}{lcccc} 
Dental related problems experience & $\begin{array}{c}\text { Yes } \\
\boldsymbol{n}(\%)\end{array}$ & $\begin{array}{c}\text { No } \\
\boldsymbol{n}(\%)\end{array}$ & $\begin{array}{c}\text { Do not know } \\
\boldsymbol{n}(\%)\end{array}$ & $\begin{array}{c}\text { Total } \\
\boldsymbol{n}(\%)\end{array}$ \\
\hline Dental problem & $20(37.0)$ & $29(53.7)$ & $5(9.3)$ & $54(100.0)$ \\
Satisfied with appearance of teeth & $31(57.4)$ & $20(37.0)$ & $3(5.6)$ & $54(100.0)$ \\
Other children make fun & $4(7.4)$ & $46(85.2)$ & $4(7.4)$ & $54(100.0)$ \\
Child misses school & $3(5.6)$ & $47(87.0)$ & $4(7.4)$ & $54(100.0)$ \\
Unable to eat hard food & $6(11.1)$ & $47(87.0)$ & $1(1.9)$ & $54(100.0)$ \\
Difficulty in chewing & $1(1.9)$ & $52(96.3)$ & $1(1.9)$ & $54(100.0)$ \\
Avoids smiling & $3(5.6)$ & $50(92.6)$ & $1(1.9)$ & $54(100.0)$ \\
\hline
\end{tabular}

Table 5 Caries experience in transfusion dependent thalassaemia children

\begin{tabular}{lccc} 
Category of age & $\begin{array}{c}\text { Prevalence of dental caries } \\
\boldsymbol{n}(\%)\end{array}$ & Mean deft (SD) & Mean DMFT (SD) \\
\hline 3-5 years old $(n=14)$ & $8(57)$ & $6.71(6.07)$ & - \\
$6-12$ years old $(n=26)$ & $20(77)$ & $3.69(4.82)$ & $1.12(1.42)$ \\
$13-17$ years old $(n=14)$ & $7(50)$ & - & $3.00(3.94)$ \\
\hline
\end{tabular}


Table 6 OHI scores in transfusion dependent thalassaemia children

\begin{tabular}{lrrr} 
& \multicolumn{3}{c}{ Category of age } \\
\cline { 2 - 4 } OHI scores & $\mathbf{3 - 5}$ years old & $\mathbf{6 - 1 2}$ years old & $\mathbf{1 3 - 1 7}$ years old \\
OHI score mean (SD) & $1.29(0.47)$ & $1.62(0.57)$ & $1.86(0.53)$ \\
Grade of OHI score & $n(\%)$ & $n(\%)$ & $n(\%)$ \\
Good & $10(71.4)$ & $12(46.2)$ & $3(21.4)$ \\
Fair & $4(28.6)$ & $13(50.0)$ & $10(71.4)$ \\
Poor & $0(0.0)$ & $1(3.8)$ & $1(7.1)$ \\
Total & $14(100.0)$ & $26(100.0)$ & $14(100.0)$ \\
\hline
\end{tabular}

Notes: Good $=0.0-1.2 ;$ Fair $=1.3-3.0 ;$ Poor $=3.1-6.0$

Table 7 Dentofacial findings in transfusion dependent thalassaemia children

\begin{tabular}{lccc} 
& \multicolumn{3}{c}{ Category of age } \\
\cline { 2 - 4 } Parameter & $\mathbf{3 - 5}$ years old & $\mathbf{6 - 1 2}$ years old & $\mathbf{1 3 - 1 7}$ years old \\
& $\boldsymbol{n}(\%)$ & $5(\%)$ & $8(57.1)$ \\
Soft tissue lesions & $1(7.1)$ & $6(23.1)$ & $0(0.0)$ \\
Discolouration & $1(7.1)$ & $9(69.2)$ & $3(23.1)$ \\
Fractured tooth & $1(7.1)$ & $5(19.2)$ & $3(21.4)$ \\
Malformed teeth & $0(0.0)$ & $12(46.2)$ & $10(71.4)$ \\
Increased overjet & $5(35.7)$ & $3(11.5)$ & $2(14.3)$ \\
Open bite & $4(28.6)$ & $4(15.4)$ & $3(21.4)$ \\
Crowding & $0(0.0)$ & $1(3.8)$ & $1(7.1)$ \\
Anterior crossbite & $0(0.0)$ & $0(0.0)$ & $4(28.6)$ \\
Posterior crossbite & $1(7.1)$ & & \\
\hline
\end{tabular}

increased overjet $(46.2 \%)$ and discolouration $(23.1 \%)$ were the common dentofacial findings among the 6-12 years old while increased overjet $(71.4 \%)$, soft tissue lesions $(57.1 \%)$, and posterior crossbite $(28.6 \%)$ were seen among the 13-17 years old. Increased overjet was seen among all three age categories. Other findings such as palatal tori, mandibular tori, geographic tongue, pale mucosa, fused teeth, peg laterals, hypoplastic teeth, talon's cusp, microdontia were also noted (see Table 7).

\section{DISCUSSION}

In this pilot study the number of registered patients with the day-care centre for transfusion was very small (62). As reported previously, it was also observed that in the present group of children, the highest prevalence of thalassaemia was observed among Malays (87\%) amongst the three prominent populations of Malaysia (Tan et al., 2010). Through the self-administered questionnaire, it was observed that the majority $(85 \%)$ of the children with thalassaemia had visited a dentist by the age of 17 years old for various dental treatment. American Academy of Paediatric Dentistry recommends the first dental visit by the first birthday and in Malaysia, a comprehensive dental programme exists for preschool children (American Academy of Pediatric Dentistry, 2020; OHP-MOH, 2019).

In the 3-5 years old group, it was surprising to observe that $35.7 \%$ of children had never visited a dentist despite some of the children having an extensive caries experience. This 
could be because parents might still be getting adjusted to the transfusion status of their child, and their child's general health has taken precedence over oral health (Fadel et al., 2020). While the children in the age group of 6-12 years old are supervised under the school dental services, it was found that the caries experience was still high $(61.5 \%)$ in this group of children with thalassaemia and despite this, $11.5 \%$ of children did not visit a dentist for further management assuming that they were referred to a dentist. In Malaysia, school dental services were started as far back as the 1950s. The school oral healthcare essentially comprises preventive and curative services and referral to a specialist where needed (OHD-MOH, 2006).

All the children in the 13-17 years old group have visited a dentist even though they are part of the school dental programme. They probably visited a dentist for further management of their oral condition because of referral from school dental services. For those who visited a dentist in the past year, the most common reason (50\%) was for "check-up or cleaning". However, in $14.3 \%$ of patients in the $13-17$ years old group, the reason to visit a dentist was "to get a tooth removed". In previous studies conducted among Jordanian and Emirati children with thalassemia, it was found that dental caries was significantly higher than the control group. The authors concluded that the chronic nature of thalassemia and the preoccupation of the patient with the condition could be the cause for neglect of oral health (Al-Wahadni et al., 2002; AlRaeesi et al., 2018). This indicates that their oral health needs attention earlier in life, to prevent loss of a permanent tooth in adolescence.

Oral hygiene practices followed by most of the study population (90.7\%) were the use of toothbrush and toothpaste twice daily. In the 3-5 years old group, $85.7 \%$ used a toothbrush and toothpaste as the main oral hygiene aid, but for $28.6 \%$ of children in this group the tooth brushing was unsupervised.
In the initial years maintaining oral hygiene is the responsibility of the parents (American Academy of Pediatric Dentistry, 2020). There is a need to create more awareness and to educate the parents of these young children about the importance of supervised brushing for their children and the impact supervised brushing can have on the oral health as well general health of their child.

A total of $37 \%$ of all the participants described having experienced a dental problem in the last year. While it was not evaluated whether they received treatment for their dental problem, this indicates that these children develop oral health issues and there is a need for early oral screening and implementation of oral health programmes for these children (Al-Raeesi et al. 2018). This would not only help in prevention, but also in early intervention with a better prognosis. Thirty-seven per cent of the sample reported dissatisfaction with the appearance of teeth. As the age of the child increased, it was observed that more children had dentofacial issues. While the open bite was more common in the 3-5 years old group, crowding and the posterior crossbite was more common in the older children. In the 3-5 years old group, the open bite could be more likely due to digit sucking or pacifier use and may not be due to skeletal changes due to thalassaemia as the changes are too early to be observed (Giuzio et al., 1991).

In this study, information related to digit sucking and pacifier use could not be obtained as the questionnaire dealt with the oral hygiene practices and information related to dental problems perceived by parents primarily. "Increased overjet" in children with thalassaemia has been ascribed in the previous literature (Perisano et al., 2012) to maxillary expansion created by the hyperactivity of the bone marrow causing the maxillary alveolus and teeth to be forwardly placed. However, in this sample, we did not notice the characteristic "chipmunk" facies (Cooley \& Lee, 1925). This sample had regular follow-ups and transfusions in the paediatric day-care. The mean pretransfusion 
$\mathrm{Hb}$ level in this study population was $9-10 \mathrm{~g} /$ $\mathrm{dl}$ and it has been reported in the previous literature that children for whom blood transfusion is started earlier in life and their haemoglobin levels are maintained well within the range are less likely to develop craniofacial deformities (Toman et al., 2011). Furthermore, due to well-maintenance of the haemoglobin levels, oral mucosa was found to be normal in all the children. Fractured anterior teeth were seen in $69 \%$ of children in 6-12 years age group while in 13-17 years age group was seen in $23 \%$ of children. This could be attributed to increased overjet in these children.

Intraoral examination revealed the presence of tori in the sample studied. Palatal tori $(9 \%)$ and mandibular tori (1\%) were observed in this small sample. Tori are commonly observed in Malaysia (Kumar Singh et al., 2017). At the same time in the children with thalassaemia, there is hyperactivity of bonemarrow. Whether the tori observed are a result of genetic predisposition or due to the pathophysiology of thalassaemia needs to be evaluated further (Perisano et al., 2012).

Dental caries was highest among the 3-5 years old with the mean deft being $6.71 \pm 6.07$ while it was $3.69 \pm 4.82$ among the $6-12$ years old, with decayed component contributing the most to the deft. The mean DMFT was $3.00 \pm 3.94$ among the 13-17 years old but it was only $1.12 \pm 1.42$ among the $6-12$ years old. The decayed component contributed to the DMFT of these two groups. The status of dental caries reported in these patients is high when compared to the National Oral Health Plan for Malaysia 2011-2020 oral health goals by the year 2020, which states that "deft in 6 years old to be less than or equal to 2 and DMFT in 12 years old to be less than or equal to 1 and in 16 years old to be less than 2" (OHD-MOH, 2011). Literature from previous research has also shown a high prevalence of dental caries in children with thalassaemia (Singh et al., 2013; Helmi et al., 2017). High caries prevalence in the younger age group indicates the need for earlier oral screening and interventions for these children as well as the implementation of oral health preventive programmes for the parents of these children who are coping with their child's thalassaemia.

This pilot study highlights the fact that while children with thalassaemia have an increased burden of therapy due to their medical condition, there is an added burden on parents due to their oral health. For the parents, their child's medical condition probably takes precedence over their oral health (Al-Raeesi et al., 2018). This study observes that children are not happy with the way their teeth look and preschool children have not visited a dentist so far. It was also observed that many of these children had malocclusions. All of this indicates that a greater emphasis needs to be given to early oral health screenings, oral health promotion and preventive oral health care in children with thalassaemia. A multidisciplinary approach involving the parents, paediatricians, paediatric dentists, orthodontists and haematologists would help in maintaining good oral health for these children.

Early referral of children with thalassaemia by the paediatricians to a paediatric dentist will help in providing anticipatory guidance to the parents towards oral health and thereby in the prevention of dental caries, and other oral conditions (Al-Raeesi et al., 2018). As school dental health services are available to school-going children up to the age of 17 years, referral of these children to specialists would also help in providing corrective and interceptive treatment to them. Preventive interventions should be the mainstay for these children rather than corrective treatment, especially by the school dental services as well as dental outpatient clinics. As many of these children report to day-care centres for their regular transfusions, at these visits, a reinforcement about the importance of good oral health should be done and directed further to dental outpatient for the necessary guidance. Early guidance from dentists and oral health 
education will aid in forming long-lasting good oral health practices that will facilitate general well-being and thereby reduce the burden faced due to oral diseases (Elangovan et al., 2013).

Thalassaemia causes serious medical, social and psychological issues for the individual (Wahab et al., 2011, Fadel et al., 2020). The families suffer a psychosocial as well as financial burden. Support groups for families with children having thalassemia can be roped in to provide information and necessary help related to preventive measures to be taken for oral health maintenance for these children. Our research has some limitations as participants were studied from only one hospital with a small size of registered patients, hence the results of the study cannot be extrapolated to the whole population. Further multi-centre studies evaluating oral health status can help in formulating oral health screening plans for these children. Our study was also limited to only oral examinations, no radiographs were done to evaluate the extent of involvement of the bones.

\section{CONCLUSION}

To the best of authors' knowledge, this clinical research was one of the first attempts to evaluate the oral health status of children with thalassaemia in Malaysia. It was observed that preschool children had more dental caries while older children had malocclusions as well as dental caries. It indicates that oral health counselling needs to be done for the parents of preschool children at the day-care centre itself to prevent dental caries. Furthermore, these children should also come under the care of a multidisciplinary team as soon as they are diagnosed so that adequate anticipatory guidance can be given. In older children, early dentofacial evaluation needs to be done so that interceptive orthodontics can be started, leading to a better prognosis.

\section{ACKNOWLEDGEMENTS}

The authors would like to thank the Director General of Health Malaysia for the permission to publish this article. The authors would also like to acknowledge the support extended by the Director of Hospital Melaka and Head of Department Pediatrics as well as the support staff of the paediatric day care, Hospital Melaka, Ministry of Health Malaysia. Besides, the authors would like to acknowledge the contribution by Professor Dr. Manonmani, Head Paediatrics, Faculty of Medicine, Manipal University College Malaysia towards her valuable inputs for the study.

\section{REFERENCES}

Al-Raeesi S, Kowash M, Hassan A, Al-Halabi M (2018). Oral manifestations and dentofacial anomalies in $\beta$-thalassaemia major children in Dubai (UAE). Spec Care Dentist, 38(1): 25-30. https://doi.org/10.1111/scd.12263

Al-Wahadni AM, Taani DQ, Al-Omari MO (2002). Dental diseases in subjects with $\beta$-thalassemia major. Community Dent Oral Epidemiol, 30(6): 418-422. https://doi.org/ 10.1034/j.1600-0528.2002.00012.x

American Academy of Pediatric Dentistry (2020). Periodicity of examination, preventive dental services, anticipatory guidance/ counseling, and oral treatment for infants, children, and adolescents. The Reference Manual of Pediatric Dentistry. Chicago: American Academy of Pediatric Dentistry. pp. 232-242.

Cooley TB, Lee P (1925). A series of cases of splenomegaly in children with anemia and peculiar bone changes. Trans American Pediatr Soc, 37: 29-30. 
Elangovan A, Mungara J, Joseph E, Guptha V (2013). Prevalence of dentofacial abnormalities in children and adolescents with $\beta$-thalassaemia major. Indian $\mathcal{F}$ Dent Res, 24(4): 406-410. https://doi.org/10 $.4103 / 0970-9290.118360$

Fadel HT, Zolaly MA, Alharbi MO, Qarah LA, Alrehili MS, Alamri AD et al. (2020). Oral health profiles and related quality of life in thalassemia children in relation to iron overload: A cross-sectional study. Int F Environ Res Public Health, 17(24): 9444. https://doi.org/10.3390/ijerph17249444

Giuzio E, Bria M, Bisconte MG, Caracciolo M, Misasi M, Nastro M et al. (1991). Skeletal changes in thalassemia major. Ital f Orthop Traumatol, 17(2): 269-275.

Greene JC, Vermillion JR (1964). The simplified oral hygiene index. I Am Dent Assoc, 68: 7-13. https://doi.org/10.14219/jada.archive .1964 .0034

Hattab FN, Hazza'a AM, Yassin OM, Al Rimawi HS (2001). Caries risk in patients with thalassaemia major. Int Den $\mathcal{F}, \quad 51(1)$ : 35-38. https://doi.org/10.1002/j.1875 $-595 x .2001 . t b 00815 . x$

Helmi N, Bashir M, Shireen A, Ahmed IM (2017). Thalassaemia review: Features, dental considerations and management. Electron Physician, 25(9): 4003-4008. https://doi.org/10.19082/4003

Kumar Singh A, Sulugodu Ramachandra S, Arora S, Dicksit DD, Kalyan CG, Singh $P$ (2017). Prevalence of oral tori and exostosis in Malaysian population - A cross-sectional study. F Oral Biol Craniofac Res, 7(3): 158-160. https://doi.org/10.1016/ j.jobcr.2017.08.008

Modell B, Darlison M (2008). Global epidemiology of haemoglobin disorders and derived service indicators. Bull World Health Organ, 86(6): 480-487.
Mohd Ibrahim H (ed.) (2019). Malaysian Thalassaemia Registry Report 2018, 1st edn. Putrajaya: Medical Development Division, Ministry of Health, Malaysia.

Oral Health Division, Ministry of Health Malaysia (OHD-MOH) (2006). Oral Healthcare for School Children in Malaysia. Putrajaya: Oral Health Division, Ministry of Health Malaysia. Retrieved 20 November 2020, from http:/ohd .moh.gov.my/images/pdf/xtvtnsop/Oral -Healthcare-for-Schoolchildren-in-Malaysia -2006.pdf

Oral Health Division, Ministry of Health Malaysia (OHD-MOH) (2011). A Lifetime of Healthy Smiles: National Oral Health Plan for Malaysia 2011-2020. Putrajaya: Oral Health Division, Ministry of Health Malaysia. Retrieved 20 November 2020, from http://ohd.moh.gov.my/images/pdf/ nohp20112020.pdf

Oral Health Programme, Ministry of Health Malaysia (OHP-MOH) (2019). Guidelines Oral Healthcare for Preschool Children. Putrajaya: Oral Health Programme, Ministry of Health Malaysia. Retrieved 20 November 2020, from https:/ohd .moh.gov.my/images/pdf/xtvtnsop/gp -ohpreschool2019.pdf

Perisano C, Marzetti E, Spinelli MS, Callà CAM, Graci C, Maccauro G (2012). Physiopathology of bone modifications in $\beta$-thalassaemia. Anemia, 2012: 320737. https://doi.org/10.1155/2012/320737

Petersen PE, Baez RJ, World Health Organization (2013). Oral Health Surveys: Basic Methods, 5th edn. Geneva: World Health Organization. Retrieved 20 November 2020, from https://apps.who.int/iris/ handle/10665/97035 
Rajajee KTSS, Jampanapalli SR, Govada J, Erugula SR, Sudheer KA, Krishna MM et al. (2017). Prevalence of dental caries, oral hygiene status, malocclusion status and dental treatment needs in thalassemic children - A cross sectional study. Sch Acad F Biosci, 5(1): 41-46.

Singh J, Singh N, Kumar A, Kedia NB, Agarwal A (2013). Dental and periodontal health status of Beta thalassaemia major and sickle cell anemic patients: A comparative study. f Int Oral Health, 5(5): 53-58.

Tan JA, Lee PC, Wee YC, Tan KL, Mahali NF, George E et al. (2010). High prevalence of alpha- and beta-thalassaemia in the Kadazandusuns in East Malaysia: Challenges in providing effective health care for an indigenous group. $\mathcal{F}$ Biomed Biotechnol, 2010: 706872. https://doi.org/10 $.1155 / 2010 / 706872$
Toman HA, Hassan R, Hassan R, Nasir A (2011). Craniofacial deformities in transfusion-dependent thalassaemia patients in Malaysia: Prevalence and effect of treatment. Southeast Asian $\mathcal{F}$ Trop Med Public Health, 42(5): 1233-1240.

Vargas CM, Monajemy N, Khurana P, Tinanoff N (2000). Oral health status of preschool children attending Head Start in Maryland. Pediatr Dent, 24(3): 257-263.

Wahab IA, Naznin M, Nora MZ, Suzanah AR, Zulaiho M, Faszrul AR et al. (2011). Thalassaemia: A study on the perception of patients and family members. Med $\mathcal{F}$ Malaysia, 66(4): 326-334. 